\title{
The Civilised Burger: Meat Alternatives as a Conversion Aid and Social Instrument for Australian Vegetarians and Vegans
}

\author{
Jemàl Nath and Desireé Prideaux
}

\begin{abstract}
Australians consume and enjoy a variety and abundance of meats. The preferred protein sources in the typical Western diet are flesh foods derived from cattle, sheep, pig, bird and aquatic species. There is, however, an emerging marketplace that offers alternatives. This paper explores the centrality of meat alternatives in the food habits and practices of Australian vegetarians and vegans. The term 'meat alternatives' refers to the variety of foods that are commonly referred to as 'mock meats'. They are plant-based products that approximate the aesthetic qualities and/or nutritional value of certain types of meat, and they are part of a quietly booming alternative food economy.

The data reported here are drawn from a grounded theory study of alternative diets. A majority of the informants in this study discussed their consumption of a variety of meat-like foods. Of all 44 informants interviewed, $34(77 \%)$ rely on and enjoy foods that they refer to as, 'burgers', 'hot dogs', 'chicken', 'schnitzels' and 'bacon'. This essay describes the social contexts in which these products are enjoyed, and explains their function, cultural meaning and ethical value to consumers.
\end{abstract}

The potential significance of meat alternatives in modernity has yet to be fully accounted for in studies of food across disciplines. An explication and critical analysis of how meat alternatives challenge, accept, or subvert established gastro-ontological assumptions about what is 'real', healthy, ethically sound, or 'authentic', will therefore contribute to broader empirical and theoretical expositions of human cultures, and food and eating practices.

\section{Introduction}

One of the earliest literary examples of a gastro-ontological awareness of fake meats as 'civilised' foods, and the tensions between their acceptance and rejection, can be discerned in Aldous Huxley's Brave New World: 
But when it came to pan-glandular biscuits and vitaminized beefsurrogate, he had not been able to resist the shopman's persuasion. Looking at the tins now, he bitterly reproached himself for his weakness. Loathsome civilized stuff! (202)

In Huxley's dystopia, John, the Savage, was confronted with a sharp distinction between the 'natural' and the synthetic world, and food within this dichotomy was a distinct marker of civilisation. In contemporary societies, fake meats such as vegetarian or vegan 'hot dogs', 'bacon', and 'burgers' continue to present a range of dilemmas for modern diners. Thus, the 'vitaminized beef-surrogate' so disdainfully cast by Huxley, is now a reality in Western and Eastern societies. Interestingly, while these foods steadily grow in popularity, they also continue to provoke uncertainty and debate.

People's food habits and practices are undeniably informed by a variety of experiences and ideas, but this essay suggests that these are always mediated through an ontological understanding of what constitutes acceptable or desirable foods. Gastro-ontology can be defined as any food-related thoughts, emotions and discourses that people develop throughout their life course. These ideas form a critical basis for decision-making about what foods should or should not be eaten. This can relate to the source of a particular food, such as plants or animals, and be guided by food preparation practices, such as whether food is raw or cooked (Lévi-Strauss). In addition, there are familial, scientific and other socially derived notions of 'good', 'bad', 'normal', or 'safe' foods, and taboos drawn from spiritual or philosophical doctrines that shape these determinations (Bourdieu 192; Nath 356). Assumptions about the value or appropriateness of particular foods, which may also incorporate opinions about their masculine or feminine qualities, constitute a gastro-ontological framework, which then enables and prompts choices and actions about what to eat. These gastro-ontological paradigms are open to challenge and revision in response to new experiences and knowledge. Vegetarians and vegans, for example, often experience a moral epiphany which disrupts established ideas about the worth of animals and the nutritional merits of eating meat, and this ultimately motivates a change in diet. Threats to gastro-ontological assumptions about food can thus serve as a catalyst for change. Paradoxically, they may also clarify and strengthen cultural norms. Therefore, an ontological view of food can help us to understand continuities, departures and developments in human food habits and practices. One area in which shifts in nutritional preferences are particularly notable is the vegetarian and vegan use of fake meats. The emergence of these products raises questions about the ways in which food is fashioned in modernity. They also offer insights into the changing nature of human perspectives on what food is, and the extent to which it signifies the social development of cultures and the technological progress of societies. 
The idea that the more progressive a society is, the further divorced it will be from its organic animal origins, is not exclusive to satirical social commentaries of the kind written by Huxley. The German social theorist, Norbert Elias, argued in The Civilising Process (originally published in 1939), that fundamental transformations in human behaviour will destabilise the dominant position of meat in Western cultures. Rather than an increased human interest in alternative social movements, this mass orientation toward meat abstention is argued as part of an evolution of manners and a growing distaste for all things 'animal'. Elias suggests that there is evidence at the family dinner table that such an evolution is underway. Whilst medieval feasts of the ruling classes proudly displayed whole joints of what was obviously an animal of some sort, modern meat production and consumption often disguises the animal origin of the displayed meat product (120). For Elias, such concealment is a deliberate attempt by meat producers and processors to avoid offending a modern consumer population that defines civilisation to be the antithesis to the animal world, and thus prefers not to encounter stark evidence of the beast origins of their food: 'The increasingly strong tendency to remove the distasteful from the sight of society deeply applies with few exceptions to the carving of the whole animal' (121).

Elias envisages a 'civilising process' that evolves gradually, in step with the popular attitudes and food practices of mainstream Western cultures. From this theoretical standpoint, meat-eaters will eventually decide that the rearing and slaughtering of animals for human consumption is an unacceptable practice for a society that deems itself to be 'civilised'. Elias considers modern vegetarians to be somewhat visionary and ahead of their time, because they have already chosen a lifestyle that he regards as inevitable for 'civilised' societies. However, it is precisely because vegetarians are in a sense too civilised that they are perceived to be radical by a meat-eating majority that fulminates over departures from time-honoured culinary practices. Elias explains that the marginal status of vegetarianism in the twentieth century exists because alternative food choices are too advanced along the civilising process continuum to have captured the popular imagination: 'these are forward thrusts in the threshold of repugnance that go beyond the standard of civilised society in the 20th century, and are therefore considered "abnormal"" (120).

Thus, Elias sees a future in which the perceived radicalism of today (vegetarianism) is destined to become tomorrow's gastronomic convention. This theory is to some extent supported by studies of meat abstention across disciplines. They indicate that for vegetarians and vegans, food and eating practices are often an extension of personally developed ideas about social justice and ethical perspectives about how humanity should develop as a species (Allen et al. 1405; Beardsworth and Keil; Kalof et al.; McDonald; Stiles 217). Elias could not, of course, have foreseen the success of Iron Chef, or a number of other forms of 
culinary entertainment that champion themes that feature the whole animal such as 'paddock to plate', 'nose to tail' and 'farm to fork', all of which celebrate nature, and reject waste and other perceived vagaries of the processed food age. Elias also underestimated the symbolic significance and social status of meat. This is most profoundly reflected by the vegetarian and vegan consumption of foods with the taste, texture and even appearance of an animal food.

The emergence of meat alternatives in Australia has been driven by the economic success of these products globally. In the United States, the vegetarian food market has become a multi-billion dollar industry, with meatless hot dogs, deli slices and bacon making impressive inroads into the traditional animalbased gastronomy of the North American continent (Liebman and Hurley 14). Evidence linking high fat meat-oriented diets to coronary artery disease and other ailments has resulted in a rise in 'transitional eating'. This does not mean that there has been a rapid growth spurt in the number of people converting to vegetarianism. Rather, it is emblematic of more meat-eaters consuming vegetarian meals on an occasional basis. This rise in 'transitional' or 'crossover' eaters in the United States has had a positive impact on the bottom line of vegetarian food companies, with sales growth at $100 \%$ to $125 \%$ from 2001 to 2007. Although soy milk boasts the greatest growth, meat substitutes continue to increase their sales (Ebenkamp 17; Kuhn 26; Roberts Jr. 24). There are a number of health reasons that would explain why 'transitional' eaters might try a meat-free meal, and these relate to the growing body of evidence linking meat and animal products with increased risk of developing arthritis, heart disease, diabetes and various cancers (Barnard et al. 972; Campbell and Campbell II, 7; Kjeldsen-Kragh 646; Thorogood et al. 1667). This explains mainstream dietary changes, but why then do vegetarians and vegans choose to indulge in meat-like foods? The data to be presented in this essay provides some answers, and raises a number of other questions about the character, constitution and future of food in modernity.

\section{The qualitative study}

The data excerpts for this paper were collected as part of a larger study of the social, ethical and spiritual dimensions of vegetarian and vegan eating practices, completed by one of the authors in 2007. The study was contextualized by first drawing from historical materials to identify political, economic and cultural turning points in the emergence of plant-based food and eating practices in Australia and other countries. Following University ethics committee approval, the data was collected between October 2003 and January 2005. Adult men and women across age groups who identified as 'vegetarian' or 'vegan' were recruited by sending flyers and information letters about the study to vegetarian 
restaurants, vegetarian societies, environmental groups, a Hare Krishna temple, Buddhist temples and two Seventh-Day Adventist Churches in South Australia. A total of 44 persons participated in audio tape-recorded interviews that ranged in length from one hour to two and a half hours. Part of the interview schedule also consisted of a brief questionnaire with closed questions ascertaining basic demographic information such as age, gender, marital status, income, occupational and educational attainment.

Grounded theory was considered to be the most appropriate method for understanding the vegetarian and vegan experience, as it allows data drawn directly from the informants to determine what ideas, themes and concepts the researcher will develop. Rather than relying on preconceived hypotheses or a set of numbers gathered from survey instruments, it is an iterative process, where the researcher becomes steeped in the data, derived in this case through in-depth interviews. Following the central tenets of this process meant that as the data collection advanced, unexpected issues raised by informants could be taken up with the next informant. The interview guideline thus expanded throughout the data collection period. This resulted in a variety of issues being canvassed and provided informants with greater scope to emphasise the unique and hitherto unknown dimensions of their vegetarianism.

The grounded approach followed a constructivist incarnation of the original Glaser and Strauss model (Charmaz 133). An important aspect of this method is the navigation of the power relationship between the researcher and the interviewees. The choice of questions on the original interview guideline was central in addressing this issue. Power relations were deemed critical in terms of the marginal dietary status of informants and the defensive posture this might provoke when informants were asked to discuss their vegetarianism. Following the pilot interviews, questions on the guideline were constructed in anticipation of rehearsed political statements that would defend or justify the participants' nutritional choices. Thus, whilst informants expected the 'why are you a vegetarian?' question, which might then be answered by a rehearsed political statement such as 'I don't eat anything with a face', they were instead asked 'How did you become a vegetarian?' During the interview the researcher therefore manipulated and 'colluded' with the interviewee to 'create and construct' stories (Nunkoosing 704) but nonetheless enabled reflexivity and talk by advancing politically neutral how questions, rather than the demanding or justifying why questions that vegetarians encounter regularly throughout their social life course. The interpretive theorising of the interview data utilised in this constructivist approach then covered 'overt processes' such as food and eating experiences at home, at work, and in other social contexts (Charmaz 146). It also delved into the implicit meanings and thinking processes of the informants regarding the kinds of foods they chose to eat and what ideas or experiences 
helped to form these choices. In keeping with established conventions for grounded style research, the resulting inferences were constantly compared throughout the interviewing process, and written analyses were supported by verbatim extracts transcribed from the data (Glaser and Strauss; Ryan and Russell Bernard; Strauss and Corbin).

\section{Findings: meat-like vegetarian food as a conversion aid and social instrument}

As noted, there are a number of reasons why a person might choose to consume mock meats which are not necessarily related to individually conceived ethical or moral discourses. These might include religious taboos related to particular animals, or the growing issue of health-related dietary restrictions. There are also food sensitivity and allergy-related avoidances. This paper mainly addresses the more predominant moral/ethical related preference for foods that do not contain meat. Two themes related to the consumption of fake animal products emerged from the data, and these themes exemplify the primary functions of meat alternatives. Firstly, they are viewed as a valuable aid for converts to a meat-free diet. The transition process to vegetarianism presents innumerable social challenges as converts attempt simultaneously to appease family misgivings and find suitable foods in an environment that heavily favours meat and animal products. One consequence of this often dramatic change is that the converts sometimes miss their once favourite home-cooked or takeaway foods. This transition process was clearly a significant and ongoing part of the life-course for converts and as such it is difficult, without the benefit of longitudinal analyses, to ascertain for each informant where it ends, and how the key constituents of their diet change over time. What is abundantly clear from the data is that meat alternatives, or mock meats, allow vegetarians, and the more marginal vegans, to enjoy familiar tastes and textures without jeopardising their utilitarian and environmental principles, and maintain a meat-free food and eating regime. Secondly, these foods are a social instrument for vegetarians and vegans. Meat alternatives have socially integrative properties. They closely resemble familiar meat and animal products and facilitate the full participation of informants at social gatherings that revolve around the consumption of meat, such as barbecues, Christmas festivities and other celebratory dinners. It should be noted here though, that the eating of mock meats, whilst popular, is not universally encouraged by all of the informants, and in some cases it is described as an unnecessary and counterintuitive act. 
Josh, an administrative officer and student on a low annual income (26-35k) described 'not dogs' 'TVP'1 and 'not burgers' as some of his staple foods, and he lamented the limited range of products that are available in Australia, in comparison to the North American varieties. Interestingly, Josh said that to cope with his transition to veganism, which for him meant completely abstaining from all meat and animal products, he substituted all his 'old favourites' with vegan alternatives. This substitution process was essential to Josh, as when he would go out he wanted to feel like he still ate 'pretty much like any other twenty-two-year-old guy' and he wanted a seamless and convenient change in the meals that he prepared at home:

I've replaced milk with soy milk obviously, TVP for mince, a lot of the fake meats I'm pretty big on. I didn't have a radical shift in the style of food I was preparing like some other vegans that don't want meat because they hate the taste of meat and change their style of cooking altogether...but the range isn't so good. I've got a lot of friends in the States, and they have like twenty different kinds of not dogs, and a lot of the Asian food is a lot more diverse as well. (Single Male, 18-25 age group)

Alice, a project manager on a moderate annual income (46-55k), is a recent convert to vegetarianism. She also talked about the importance of convenience and how meat-like meals make the transition to vegetarianism easier:

I wish the range they had in Coles was more available elsewhere, like the Sanitarium range. I live in the Adelaide Hills so it's okay, but I think when you work full-time you need easy options. If you eat meat you can buy things like chicken fillets that you just cook and chuck on a salad and then you've got a meal. When you're doing vego stuff, if you have a salad without anything else, it's not necessarily filling. So you want something else, so you need pasta and that kind of thing. So the easy stuff like not dogs, vegetarian schnitzels, that kind of thing I tend to rely on during the week. (Partnered Female, 26-34 age group)

Informants in this study who raise vegetarian children were especially aware of the high social status of meat and animal products. Eve, a former retail worker and now full-time postgraduate student on a low annual income (16$25 \mathrm{k})$, converted to vegetarianism over a decade ago. Her daughter joined her in converting and is still a vegetarian. Despite giving up meat and almost all animal products, they are still committed to finding ways of maintaining an active social life of entertaining and eating with their non-vegetarian friends. The

1 TVP stands for textured vegetable protein, the most widely produced meat substitute in Western nations. It comes in granules with a hamburger mince consistency and has for decades been used as a 'meat extender' in commercial meat patties (Scarborough 1). 
importance of meat alternatives for parties, especially her daughter's birthday celebrations and other occasions, is a key motivational factor in Eve's desire to source and sample a phenomenal range of meat substitutes:

I love all sorts of new things. There are vegetarian roasted chicken pieces which are a real favourite. We use them in stir fries, kebabs, we marinate it and it's a very big hit with our meat-eating friends especially. They could not believe that it wasn't chicken and that all the pieces were so perfect with no nasty animal bits. We also do vegetarian chicken fillet burgers, so vegetarian chicken fillet things crumbed, and made into a burger, that's really nice. Vegetarian sausages are popular here and they are good standby things. There are a couple of varieties of vegetarian beef; one's really good for making fake steak sandwiches, and the other for vegie beef goulash. Oh, there is also a dried version that makes a damn fine vegie beef, onion and mushroom pie. (Partnered Female, 4350 age group)

The aforementioned products are a fundamental part of Eve's social actions and interactions with family and close friends. She further suggested that it has taken her over a decade to source these products, which are not all readily available from the local supermarket. Other informants similarly described their delight at finding specialty items such as 'vegetarian prawns' and 'vegetarian squid'. These products are made from taro or yams that provide a chewy texture and include seaweed extract to simulate a 'seafood' taste. They are imported from the Asia-Pacific region and are intermittently available at a small number of Asian grocery stores. The key point here is that informants find the experience of sharing vegetarian food with non-vegetarians a valuable opportunity simply to enjoy a variety of cruelty-free tastes and textures that everyone finds familiar, acceptable and highly pleasing to the senses.

These ideas have their origins in Buddhist philosophy. Also known as 'Buddha's meat', mock meat was created in the monasteries of China over two thousand years ago. In ancient China, the Buddhist religion prohibited the taking of life. However, Chinese hospitality required that hosts defer to the culinary tastes of their guests. In accordance with these beliefs, special efforts were made in the preparation of gourmet vegetarian meals that tasted and looked like popular flesh foods such as pork, beef, poultry and seafood (Neilson 1). Today, the quest to convincingly render soybeans, taro, mushrooms or gluten into traditional meat favourites has ventured out of the temple kitchens of Buddha devotees and into the global marketplace. Throughout the Western world and Asian regions, there are small numbers of restaurants that marry carnivorous tastes with vegetarian practices. They attempt to attract meat-lovers and curious 
vegetarians by offering plant-based versions of classic meat dishes, from the ubiquitous lemon chicken, to the lesser known traditional Chinese delicacies, such as vegetarian intestines or vegan abalone (Beattie 1).

Buddhist informants are acutely aware of the social and cultural significance of meat and animal products in their original ethnic foodways and in Australian cultures. Lishi, a Sino-Vietnamese Buddhist now residing in Australia, partowns a South Australian vegetarian restaurant that attempts to appeal to nonvegetarians with a variety of meat-like foods. She described why these foods are an important addition to the menu in both her restaurant and her diet:

we still have fried chickens and fried prawns and honey chickens, beef with black bean sauce, sweet sour pork and all those yummy dishes normally a meat-eater would prefer to eat. Also when I think back to when I was a meat-eater, I wasn't actually missing meat, it was the texture that I missed, the taste I missed and the kind of dishes that I missed. (Single Female, 35-42 age group)

The desire for social integration is also significant within familial contexts. Five of all 44 informants in this study $(11 \%)$ are, in a nutritional sense, in a mixed marriage, because they are partnered with non-vegetarians. Michelle, a schoolteacher on a low to moderate annual income (36-45k), is a Seventh-Day Adventist and was born and raised as a vegetarian, but she is married to a nonvegetarian Adventist. She describes herself as somewhat of a reluctant meat abstainer because of the social constraints brought about by the marginal status of vegetarianism in Australia. In Michelle's home, meat substitutes have a role in maintaining family commensality, that is, the widely established practice of people dining together, especially at the same table. She explained that it was essential to her that despite their dietary differences, the family could all sit down and eat together because she had suitable alternatives:

Usually when I have things like that I would just have salad or vegies with it. So when I'm cooking for the family quite often they will have their lamb chops and I will have my vegetarian version and we will all have salad or vegies with it, so it is a bit like a meat and three vegetable meal without the meat portions for me. (Married Female, 35-42 age group)

In contrast to vegetarian converts who were born and raised with an abundance of meat and animal products in their diet, Adventist informants often have little or no experience of eating meat, and they describe meat alternatives as a lifelong staple. Consequently, meat-like foods are deeply embedded in their diet and consciousness. Michelle and other Adventist informants made specific mention of meat alternative products made by Sanitarium, a health-food company that 
has a strong affiliation to the nineteenth-century American Christian Physiology Movement and also with the Adventist church (Le Blanc 91; Levenstein 93). In Australia, this company has manufactured meat alternatives for decades and was well known by the majority of informants. Carol, an Adventist, who receives a low annual income as an aged care worker (16-25k), was born and raised as a vegetarian. Now in her sixties, she has consumed a variety of traditional meat substitutes for over half a century:

I was brought up on nutolene and nut meat, that's been around since forever. In the 1920s those products came out and so yes I have had them all my life. I love their frozen products like the soy cutlets and schnitzels and things. I'm not so keen on some of the Longa Life ${ }^{2}$ products, they are the ones in the refrigerator, but that is because I am an older person and they have a more modern flavour. I'm not happy with smoky flavours at all, can't stand them and I never could. So I do avoid the ones that sound like they will have a smoky flavour, but beyond that I am fairly flexible with what I eat. (Single Female, 59-66 age group)

Another informant who was born into an Adventist vegetarian family talked at length about meat alternatives and vegetarian 'junk foods' that continue to constitute a significant portion of his diet. Mal is a builder on a moderate annual income (56-65k). Although he is no longer a member of the Adventist Church he still abstains from most meats and some animal products because he dislikes the smell and taste. He also talked about consuming new products as well as his preferred staple of some fast foods and meat-like foods:

McDonald's advertised that they have vegie burger, and in my opinion it taste like shit! (laughter) I wasn't impressed with that at all. I went to Burger King in New South Wales when I was there and they were quite nice. We were staying near Darling Harbour and there was a Burger King near there and we went and had a vegie burger. I mean, I go often to a fish and chip shop and I'll have a vegie burger you know and they're lovely, you know... I've always had vegie sausages and all that, ready burger and nutolene, I quite like, but most people haven't heard of that. (Married Male, 51-58 age group)

As mentioned, while most of the vegetarians in this study have eaten mock meats, a smaller group stated that they did not regularly consume them, and some of these informants questioned the logic of a vegetarian wanting to eat something that resembled meat. George, a graphic designer on a low annual

2 The informant is referring to a vegan oriented food company named Longa Life, which made a small variety of meat-like products such as 'not bacon', 'not dogs' and 'not burgers'. The company no longer trades, but their range was taken over by Sanitarium, who have remained faithful to the original recipe, relaunching them under the new 'Vegie Delights' label (Ryan 1). 
income (26-35k), flatly stated that he and his partner felt that it was just, 'a bit weird' to purchase products such as vegetarian burgers and hot dogs. However, their curiosity did lead them to a memorable and somewhat dramatic first encounter with meat alternatives:

We went to a restaurant, a big Chinese restaurant. It was a fantastic place, and they had this monk menu because of a lot of the Chinese were Buddhist monks, and they eat there, and I guess in their particular clan they have this tradition, because monks get bored right? So they make the best mock meat they can out of tofu, all these sculpted things. So I thought: I'm going to order the vegetarian flathead! And no shit, it came out and it was really like a flathead! It was like a baked fish (laughter) texture and everything. It was so realistic and I thought man, shock horror! I didn't enjoy it very much because the sauce wasn't fantastic, but the weirdness of it! So we really haven't had very much, but we know a lot of vegos have sausages and that sort of stuff. (Married Male, 26-34 age group)

One vegan informant, Jelena, a part-time student and administrative officer on a low annual income (16-25k), was appalled by the idea of eating meat-like foods and totally boycotted such products, with a small exception made for some types of vegetarian burgers, and only in immediate familial social contexts:

at home we don't ever eat things like that. It doesn't appeal to us because the thought of eating meat is repulsive so the thought of sitting down to something that tastes or resembles meat is repulsive and I can't understand why anyone would want to do that. Even things like mock meat we wouldn't have, I mean sometimes you can get sandwich meats and stuff which are vegetarian, and we wouldn't get that. The only thing that we eat when we go to mum and dad's which I don't mind is vegetarian burgers, vegetarian patties. They don't look like meat; they're just patties. (Married Female, 26-34 age group)

The six informants from the total sample who converted to vegetarianism as part of their Hare Krishna devotional service (14\%), are a standout group of vegetarians who are also not interested in any sort of vegetarian 'junk food' or meat alternative. Krishna Das, a Hare Krishna priest on a low annual income (Under 15k), exemplified the brief and to the point devotee responses on this matter and certainly did not mince words when asked if he had tried vegetarian fast foods and meat alternatives: 
No I've never had that sort of thing. My understanding is that there is no need to substitute meat. We are not meant to eat meat. My understanding is that we are constitutionally vegetarian beings. So no fast food and I would not even look in McDonald's. (Single Male, 26-34 age group)

This informant is certainly not alone in his attitude towards McDonald's. However, for the majority of informants who converted to vegetarianism, memories of the greasy burger or hot dog when out with friends, the roasted chickens, the pan-fried sausages, the schnitzels at the family dinner table, are all indelibly etched in their minds long after their dietary change. These informants do reject the flesh foods that are commonly sold at fast food outlets, or cooked on the barbecue in the backyard and on the grill at the fish and chip shop, because of the living animal origins of the foods served in such places. Yet, they do not relinquish the memory, nor do they underestimate the social meaning and worth of sharing a burger or a hotdog with friends, or the commensal pleasures of a hearty egg and bacon breakfast with their families.

\section{Conclusion}

The comments of the informants throughout this essay suggest that meat alternatives are much more than guilty pleasures or ersatz food substances that are consumed merely to satiate meat cravings. There is a discernible social dimension to the informants' incorporation of meat alternatives in their vegetarian diets. It is also clear that products such as vegetarian or vegan sausages, bacon and hot dogs are effective social instruments. They seem to perform their tasks well and are the ultimate means by which vegetarians participate in and enjoy potentially uncomfortable situations, such as barbecues or Christmas feasts. Rather than altering their social circle, vegetarians and vegans choose foods that are socially efficacious as well as being pleasing to the senses.

There are however, a number of public health and ethical dilemmas that arise from the emergence of plant-based processed foods. The findings presented highlight how vegetarian diets could become nutritionally inadequate. As the well-known Australian nutritionist and author, Rosemary Stanton, warned over a decade ago, 'Being vegetarian does not, in itself, guarantee a healthy diet' (vi). Stanton, who is not a vegetarian, is one of very few nutritionists in Australia who was willing to endorse vegetarian diets in the late 1990s and publish medicalscience based tips for 'healthy vegetarian eating'. The data presented in this essay does confirm Stanton's warning. The informants' consumption of mock meats clearly indicates that some vegetarians might make nutritionally poor choices on a regular basis, although it appeared that none of the informants in 
this study chose to live exclusively off a range of meatless junk foods. These products are usually defined as an indulgence or as an accompaniment to fresh, plant-based whole foods.

In varying degrees, these processed foods challenge the gastro-ontological security of some vegetarians and vegans, and further research with nonvegetarians would undoubtedly reveal mixed reactions. For example, highly health conscious consumers might appreciate a convenient product that contains no saturated animal fats and cholesterol, but be deterred by high sodium or sugar levels. Then, there are the environmental considerations. Vegans might like a little fake bacon, burger, or sausage, but be dismayed by the wasteful packaging and general resource waste typical of processed food industries. Some writers have already questioned whether these foods are ethically sound. Michael Pollan represents a growing number of 'foodies' who encourage more plant-based eating, but are nonetheless concerned with humanity severing ties with 'nature'. Pollan's In Defence of Food is highly critical of the soy industry, and he asks readers to regard 'nontraditional' foods with scepticism (176). In a disquisition on the moral malaise inherent in vegetarianism, Keith Tester is more cynical. Citing the meat-free frozen food sales that are worth over 100 million pounds annually in the United Kingdom, he argues that factories which mass produce meat-free meals like the Linda McCartney range (multinational owned) resemble the factory farm and its McDonaldized operational structure:

There can be little or nothing 'natural' about the production processes which are relied upon by the plant in Norfolk. This is most definitely a long way from what Peter Singer undoubtedly had in mind when he made his call for vegetarianism. (219)

Tester is rightfully ambivalent about the ethical nature of vegetarian foods when they are manufactured and marketed in the same manner as their animal-based counterparts. However, he did not fully explain why this should matter. Does a vegetarian who wants to live a cruelty-free existence also have to abandon all of the fundamental principles, products and structures of the free-market, capitalism and modernity? Perhaps because of the processing and convincing meat-like imagery alone, the consumption of these products can easily be interpreted as a compromise in the core values of vegetarianism. Yet, in the Australian study, the majority of informants who indulge in meat alternatives maintain that if eating foods such as vegetarian sausages is a compromise, it is so in an aesthetic sense only, and is certainly not a moral concession. Put simply, animals are not reared and slaughtered for vegetarian bacon or chicken; no animals are killed, nor are their basic freedoms interrupted. A major theme for lovers of meat alternatives in this study was that they want to enjoy and fully participate in meat-oriented feasts such as Christmas and barbecues, but they also want to subvert the regular animal-based feature of these occasions 
with various meat substitutes. One informant, Eve, exemplified the views of the majority of informants regarding meat-like foods with a clearly articulated moral disclaimer for why vegetarians and vegans should freely enjoy meat alternatives:

We like all this stuff because it's a big joke, as long as it didn't die! I never said I didn't like the taste and texture of meat, I just don't like what it is, where it comes from, and as long as it didn't die I'm happy to eat meat alternatives. (Partnered Female, 43-50 age group)

It could be argued that the vegetarian penchant for meat-free hot dogs, burgers and other meat alternatives is evidence of compliance with cultural and gastronomic norms that place a premium on meat and animal products. Conversely, the informants' consumption of meat-like foods could be interpreted as a form of resistance to these norms, as these products are chosen precisely because they usually contain no animal-based ingredients. Irrespective of whether the consumption of meat alternatives is indicative of acceptance, resistance, or subversion of cultural norms, there is more of an irreverent than reverent quality to the informants' understanding of the status of meat and animal products in Western cultures. They certainly view plant-based nutrition as the key ingredient for transforming their respective communities into more egalitarian and cruelty-free spaces. Provided, therefore, that there is no 'real' meat on their plates, vegetarians and vegans in this study acknowledged with varying degrees of impertinence and humour that they can, metaphorically speaking, have their civilised burger and eat it too!

Dr Jemàl Nath teaches Health Psychology and Sociology in the School of Nursing and Midwifery at Flinders University. His research interests are interpretive and critical approaches to food, health, science and the body. He has published recently on Australian gendered eating customs and the relationship between religion, biospirituality, health and food.

Desireé Prideaux is a PhD student and part-time teacher in the English Department at Flinders University. Her research and writing interests include the gender political contexts of Australian food and literary cultures, women writers and golden age crime fiction.

\section{Acknowledgements}

The authors would like to thank the editors and the independent reviewers for their valuable theoretical and structural recommendations. Thanks are also due to Dr Nathan Manning for his comments and suggestions on an earlier draft of this essay. 


\section{Works cited}

Allen, Michael W., et al. 'Values and Beliefs of Vegetarians and Omnivores.' Journal of Social Psychology 140.4 (2000): 405-422.

Barnard, Neil D, et al. 'Effectiveness of a Low-Fat Vegetarian Diet in Altering Serum Lipids in Healthy Premenopausal Women.' American Journal of Cardiology 85.8 (2000): 969-972.

Beardsworth, Alan, and Teresa Keil. 'Health-Related Beliefs and Dietary Practices Among Vegetarians and Vegans: A Qualitative Study.' Health Education Journal 50 (1991): 38-42.

—. 'The Vegetarian Option: Varieties, Conversions, Motives and Careers.' The Sociological Review 40 (1992): 253-93.

—. Sociology on the Menu. London: Routledge, 1997.

Beattie, Alexa. 'Find Great Mock Meat.' Washington Post, 9 October 2005. <http://www.washingtonpost.com/wpdyn/content/article/2005/10/06/ AR20051006108> Accessed 15 May 2006.

Bourdieu, Pierre. Distinction: a Social Critique of the Judgement of Taste. London: Routledge, 1984.

Campbell, T. Colin, and Thomas M. Campbell II. The China Study. Dallas, Texas: Benbella Books, 2006.

Charmaz, Kathy. Constructing Grounded Theory: A Practical Guide Through Qualitative Analysis. London: Sage, 2006.

Ebenkamp, Becky. 'Rationing Meat.' Brandweek 21 (2002): 17.

Elias, Norbert. The Civilizing Process: The History of Manners. Trans. Edmund Jephcott. Oxford: Basil Blackwell, 1978.

Glaser, Barney, and Anselm Strauss. The Discovery of Grounded Theory: Strategies for Qualitative Research. Chicago: Aldine, 1967.

Huxley, Aldous. Brave New World. London: Chatto \& Windus, 1964.

Kalof, Linda, et al. 'Social Psychological and Structural Influences on Vegetarian Beliefs.' Rural Sociology 64.3 (1999): 500-511.

Kjeldsen-Kragh, Jens. 'Controlled Trial of Fasting and One-Year Vegetarian Diet in Rheumatoid Arthritis.' Journal of the American Medical Association 267.5 (1992): 646-647. 
Kuhn, Mary Ellen. 'Courting Crossover Vegetarian Consumers.' Food Processing 57.6 (1996): 26-8.

Le Blanc, Ronald D. ‘Tolstoy's Way of No Flesh: Abstinence, Vegetarianism, and Christian Physiology.' Food in Russian History and Culture. Ed. Musya Glants and Joyce Toomre. Bloomington: Indiana UP, 1997. 81-96.

Levenstein, Harvey A. Revolution at the Table: The Transformation of the American Diet. New York: Oxford UP, 1988.

Lévi-Strauss, Claude. The Raw and Cooked. London: Jonathan Cape, 1970.

Liebman, Bonnie, and Jayne Hurley. 'No Baloney: Meatless Hot Dogs, Deli Slices and Bacon.' Nutrition Action Healthletter 25.8 (1998): 14-16.

McDonald, Barbara. "'Once You Know Something, You Can't Not Know It": An Empirical Look at Becoming Vegan.' Society and Animals 8.1 (2000): 1-23.

Nath, Jemàl. "God is a Vegetarian": The Food, Health and Bio-spirituality of Hare Krishna, Buddhist and Seventh-Day Adventist Devotees.' Health Sociology Review 19.3 (2010): 356-368.

Neilson, Leslie Marian. 'Asian "Mock Meats".' World Music News Today, 14 March 2006. <http://www.globalrythym.net//Food/AsianMockMeats.cfm Accessed May 15 2006>

Nunkoosing, Karl. 'The Problems with Interviews.' Qualitative Health Research 15.5 (2005): 698-706.

Pollan, Michael. In Defence of Food: The Myth of Nutrition and the Pleasures of Eating. London: Penguin Group, 2008.

Roberts Jr, William A. 'Meatless in the Mainstream.' Prepared Foods 171.3 (2002): 23-5.

Ryan, Rosemary. 'Aussies Urged to go Meat-free.' B\&T, 19 December 2005. <http://www.bandt.com.au/news/e2/0c034ee2.asp> Accessed 15 May 2006.

-. 'Butchers Boogie to Boost Meat.' B\&T, 18 February 2002. <http://www. bandt.com.au/news/8e/0c00af8e.asp> Accessed 29 Oct. 2006.

Ryan, Gery W., and H. Russell Bernard. 'Data Management and Analysis Methods.' Handbook of Qualitative Research. Eds. Norman K. Denzin and Yvonne S. Lincoln. Thousand Oaks: Sage, 2000. 769-802.

Scarborough, Stephanie. 'TVP-What the Smell is it?' Vegetarian Baby and Child, 16 May 2005. <http://www.vegetarianbaby.com/cheapvegan/tvp. shtml $>$ Accessed 16 May 2006. 
Stanton, Rosemary. Healthy Vegetarian Eating. St. Leonards: Allen \& Unwin, 1997.

Stiles, Beverly L. 'Vegetarianism: Identity and Experiences as Factors in Food Selection.' Free Inquiry in Creative Sociology 26.2 (1998): 213-225.

Strauss, Anselm, and Julia Corbin. Basics of Qualitative Research: Grounded Theory Practices and Techniques. California: Sage, 1990.

Tester, Keith. 'The Moral Malaise of McDonaldization: The Values of Vegetarianism.' Resisting McDonaldization. Ed. Barry Smart. London: Sage, 1999. 207-221.

Thorogood, Margaret, et al. 'Risk of Death from Cancer and Ischaemic Heart Disease in Meat and Non-Meat Eater.' British Medical Journal 308.6945 (1994): 1667-71. 